\title{
ALGUNAS REFLEXIONES Y PRECISIONES EN TORNO A LA TEMPRANA HISTORIOGRAFÍA DE LA PINTURA RUPESTRE EN LAS CALIFORNIAS
}

\author{
Por \\ Felipe I. Echenique March*
}

\begin{abstract}
RESUMEN
En los últimos ańos investigadores nacionales y extranjeros han enfocado su atención hacia la llamada pintura rupestre. Con los resultados de sus trabajos han logrado despejar diversas incógnitas y mitos en torno a esta forma de expresión de los antiguos californios.

En este documento, sin pretender invadir el campo de la arqueología, se aportan algunas precisiones y reflexiones sobre las representaciones culturales pictóricas, pictográficas y petroglíficas, desde un enfoque histórico. Para ello se recurre al análisis y crítica de las fuentes escritas, en particular aquellas referentes a la temprana historiografia de la pintura rupestre de los grupos indígenas californianos.
\end{abstract}

\begin{abstract}
During the last few years both Mexican and foreign researchers have focused their attention on prehistoric painting. As a result of their labors, they have been able to solve several mysteries, as well as dispelling some myths revolving around this form of expression among the ancient Californians.

This document, without any intention of invading the field of the archeologist, discusses some clarifications and reflections having to do with pictorical cultural representations, pictographs, and petroglyphs, from a historical standpoint. To do so, it turns to an analysis and critique of written sources, particularly those which refer to the early history of prehistoric painting produced by indigenous groups in the Californias.
\end{abstract}

* Investigador de la Subdirección de Estudios Históricos del Instituto Nacional de Antropología e Historia (INAH). 
En la actualidad, la llamada pintura rupestre ha recibido la atención de estudiosos. Lo comprueba la puesta en marcha del megaproyecto del INAH "Arte rupestre en Baja California Sur" (sierra de San Francisco) y que no es más que la continuación y consecuencia natural de otra serie de investigaciones que en los últimos años han elaborado nacionales y extranjeros. Los resultados de estos estudios comienzan a ser publicados y las incógnitas y mitos en torno a sus objetos de análisis, son despejados. A don Antonio Pompa y Pompa - como en otros muchos temas-, se le debe el hecho de haber llamado la atención sobre este tipo de manifestaciones culturales cuando en 1958 presentó su ponencia "La escritura petroglífica rupestre y su expresión en el noroeste mexicano", durante el Primer Congreso de Historia Regional realizado en Mexicali, Baja Califomia. Pionero en nuestro siglo por el interés en precisar la naturaleza y significado de aquellas expresiones culturales pictóricas, pictográficas y petroglíficas, se ofrecen aquí las siguientes reflexiones sobre el inicio historiografico de las mismas, con la sentida pena de ya no poder discutirlas con quien tanto luchó por puntualizar la naturaleza de las fuentes, de sus contenidos y sus alcances para "El tercer hombre" en su devenir histórico. ${ }^{1}$

No soy arquélogo y por tanto el enfrentarme a las pinturas rupestres, materia de estudio especializado de aquéllos, puede resultar aventurado y hasta poco profesional. Pero no trataré el tema como lo harían ellos, sino como lo tenemos que hacer los historiadores: desde la perspectiva del análisis de las fuentes escritas referentes a dichas manifestaciones culturales; esto es, desde la crítica interna de la documentación existente.

Sería imposible hacer el análisis historiografico de todo lo que se ha escrito al respecto, por lo que me limitaré a realizar algunas precisiones y reflexiones en torno a la temprana historiografía de la pintura rupestre en las Californias, ya que siguen siendo fuentes testimoniales con significado y sentidos propios.

El libro I, capítulo XVII, de la Historia de la antigua o Baja California, de Francisco Xavier Clavijero, inicia así:

Poca diferencia de las citadas bestias eran en la manera de vivir los salvajes habitantes de la California. Pero atendiendo a los pocos vestigios de antigüedad que allí han quedado, es fácil persuadirse que aquella vasta península estuvo antes habitada por gentes menos bárbaras que las que hallaron en ella los españoles; porque los jesuitas, en los últimos años que estuvieron allí, descubrieron en los montes

1 Una versión preliminar al presente ensayo se presentó en noviembre de 1994, en las "Jornadas Homenaje in memoriam Antonio Pompa y Pompa", Guanajuato, Guanajuato. 
situados entre los 27 y 28 de latitud, varias cuevas grandes cavadas en piedra viva, $\mathrm{y}$ en ellas pintadas figuras de hombre y mujeres decentemente vestidas y de diferentes especies de animales. Estas pinturas, aunque groseras, representan distintamente los objetos, y los colores que para ellas sirvieron, se echa de ver claramente que fueron tomados de las tierras minerales que hay en los alrededores del Volcán de las Vírgenes. Lo que más admiró a los misioneros fue que aquellos colores hubiesen permanecido en la piedra por tantos siglos sin recibir daño alguno ni del aire ni del agua.

No siendo aquellas pinturas y vestidos propios de las naciones salvajes y embrutecidas que habitaban la California cuando llegaron a ella los españoles, pertenecen sin duda a otra nación antigua, aunque no sabemos decir cuál fue. Los californios afirman unánimemente que fue una nación gigantesca venida del Norte. Yo no pretendo que se les dé credito a esta tradición; pero ciertamente no puede dudarse que haya habido allí antiguamente algunos hombres de desproporcionada talla, como se infiere de varios huesos exhumados por los misioneros. Entre otros el padre José Rotea, misionero de [San Ignacio] Kadakaamang, hombre curioso, exactoy sincero, habiendo sabido que en un lugar de su misión llamado ahora San Joaquín, había un esqueleto gigantesco, mandó cavar, y halló efectivamente todo el espinazo, aunque con las vértebras ya desunidas, una canilla, una costilla, varios dientes, y señaladamente un gran fragmento de cráneo. Pudo haberse hallado todo el esqueleto si un torrente vecino no hubiese corróido el suelo y arrancado de allí algunos huesos. La costilla, aunque no estaba entera, tenía todavía como dos pies de larga. La canilla no pudo medirse, porque se rompió al sacarla. Considerada pues la magnitud del cráneo medido el lugar que ocupaba todo el esqueleto y comparadas sus vértebras con las de un esqueleto común, se cree que el hombre a quien pertenecieron aquellos huesos tenía casi once pies de altura.

El mismo misionero reconoció algunas de las cuevas mencionadas, de las cuales describe una. Tenía de largo unos 50 pies, de ancho quince y otro tanto de alto y estaba formada a manera de bóveda apoyada sobre el pavimento. Como por la parte de su entrada estaba toda abierta, recibía bastante luz para poder observarse las pinturas de su parte interna y más alta. En ella estaban representados hombres y mujeres con vestidos semejantes a los de los mexicanos, pero absolutamente descalzos. Los hombres tenían los brazos abiertos y algo levantados, y una de las mujeres estaba con el pelo suelto sobre la espalda y un penacho en la cabeza. Había también varias especies de animales tanto de los nativos del país como de los extranjeros (Clavijero, 1970:48-50). 
Ahora bien, todo esto que escribio Clavijero se encuentra expuesto también en el texto del padre Miguel del Barco, pero con serias diferencias en su estructura, por lo cual lo transcribimos:

En los últimos años que los jesuitas estuvieron en la California comenzó a correr la noticia de que antiguamente hubo gigantes en esta tierra; aunque no nativos de ella sino venidos del norte. El misionero de San Ignacio [Kadakaamang], que en aquel tiempo era el padre Joseph Rothea, supo que en los territorios de su misión se hallaban todavía restos de esta antigüedad extraordinaria, los cuales quiso conocer por sí mismo, como lo ejecutó del mejor modo que le fue posible. Y para que no se pierda la memoria de una cosa tan rara, rogué al citado misionero, que escribiera lo que averiguó en esta materia. Hízolo así, y su escrito lo traslado aquí a la letra, para mayor satisfacción de los lectores de que esta noticia la demos sin alguna alteración, según lo merece este sujeto, digno de toda fe. Dice, pues, así:

"Los fundamentos que, probablemente persuaden hubo gigantes en la California, se reducen a tres. Primero, los huesos que en varias partes se encuentran. Segundo, las cuevas pintadas, lo tercero, la voz común de los ancianos. Cuanto al primero: en la misión de San Ignacio [Kadakaamáng] hay un lugar de ranchería llamada San Joachín. En este lugar me dijo un indio, de edad como de treinta años, que, siendo él niño, se entró al monte con otros de su edad, y dieron con un esqueleto humano de extraordinaria grandeza. Dio de ello aviso a su padre, y éste le respondió que ya lo había visto, y que siempre que pasaban por aquel sitio en busca de venados, se paraban a contemplar aquella grandeza de cuerpo. Pregúntele yo a este viejo, $Y$ contestó que era así. Pasé a dicho lugar, en el que ya no se veía nada, porque con el decurso de los tiempos se había formado o crecido un pequeño barranco, y robada la tierra vecina al cuerpo, había éste caído y estaba sepultado. Yo registré la ladera arriba y abajo, y noté que de la parte superior no se encontraba hueso alguno; y sí varios por la ladera abajo. Pregunté, $¿$ dónde tenía la cabeza y dónde los pies? Y medido el sitio, hallé que ocupaba el largo de cuatro o cinco varas.

Comencé a cavar, y de hecho di con un pedazo de cráneo bien grande, el que, por más cuidado que puse, se desmoronó al sacarlo. Poco más adelante descubrí los huesos o vértebras del espinazo, seguidos aunque sin unión; los cuales llevé a la cabecera de la misión, y, cotejados con los de nuestros muertos, vi que los del gigante eran como tres tantos mayores. Di también con una costilla, que, descubierto todo lo que de ella había quedado, la medí, y sería como de tres cuartas, aun faltándole algo de uno y otro cabo. Descubrióse más abajo, en el mismo sitio medido, un gran hueso, canilla del cuadril, que no tuve el 
gusto de verlo entero; porque ocupado yo en procurar sacar entero el cráneo, pues éste era la principal prueba de esta historia, lo rompieron los que se adelantaron a desenterrarlo. Otros varios huesos encontré allí mismo; parte enterrados y parte rodados por la ladera, como dientes y muelas correspondientes al cráneo, espinazo, costilla, etcétera.

Fuera de esto que, como digo, desenterré en este paraje, tuve en mi misión los fragmentos de una quijada, que de su misión [Santa Gertrudis] me envió el padre Jorge Retz que me afirmó que él la vió entera, y que así me la despachó. Lo que de ella llegó a mis manos visible, como dientes y muelas, eran semejantes a los que tengo dicho.

Pasé después a registrar varias cuevas pintadas; pero sólo hablaré de una, por ser la más especial. Esta tendría de largo como diez o doce varas, y de hondo unas seis varas: abierta de suerte que toda era puerta por un lado. Su altura (según me acuerdo), pasaba de seis varas. Su figura como de medio cañón de bóveda, que estriba sobre el mismo pavimento. De arriba hasta abajo toda estaba pintada con varias figuras de hombres, mujeres y animales. Los hombres tenían un cotón [especie de sayo ancho y cerrado que se pone como camisa] con mangas: sobre éste un gabán, y sus calzones; pero descalzos. Tenían las manos abiertas y algo levantadas en cruz. Entre las mujeres estaba una con el cabello suelto, su plumaje en la cabeza, y el vestido de las mexicanas, llamado gitipil. Las de los animales representaban ya a los conocidos en el país, como venados, liebres, etcétera, ya otros allí incógnitos, como un lobo y un puerco. Los colores eran los mismos que se hallan en el Volcán de las Vírgenes, verde, negro, amarillo y encarnado. Se me hizo notable en ellos su consistencia; pues estando sobre la desnuda peña [expuestas] a las inclemencias del sol y agua, que sin duda los golpea al llover, con viento recio, o la que destilan por las mismas peñas de lo alto del cerro, con todo esto, después de tanto tiempo, se conservan bien perceptibles.

Ya con estos principios, junté los indios más ancianos de la misión para averiguar qué noticia había entre ellos acerca de esto. Lo mismo encargué que hicieran en las misiones de Guadalupe, y Santa Rosalía, sus misioneros (que entonces eran de la primera el padre Benno Ducrue y, de la segunda, el padre Francisco Escalante), y, según me acuerdo, sucedió la contingencia de hacer la averiguación (al menos uno de ellos), y el mismo día que yo los ejecutaba con los míos. Todos convinieron en la sustancia, es a saber que de padres a hijos había llegado a su noticia que, en tiempos muy antiguos, había venido del norte porción de hombres y mujeres de extraordinaria estatura, venían huyendo unos de otros. Parte de ellos tiró por lo largo de la costa del mar del Sur; y de éstos me dijeron, se ven aún los abrigos que formaban 
y son como los que usan los mismos californios, pero muy grandes en su comparación. No pude registrar con mis ojos estas memorias, que son las únicas que de estos primeros quedaron. La otra parte de ellos tiró por lo áspero de la sierra, y ellos son los autores (decían) de dichas pinturas. A la verdad las que yo ví, lo convencen; porque, tantas, en tanta altura, sin andamios y no otros instrumentos aptos para el efecto, sólo hombres gigantes las pueden haber pintado. Decían por último, que parte de ellos murieron a manos los unos de los otros, y parte también mataron los mismos californios, que no sufrían en sus tierras habitadores tan extraños." Hasta aquí la relación —dice Del Barco y continúa su relato-. El misionero de Santa Rosalía, arriba citado, dice que, entre sus indios, se conserva la misma noticia de gigantes que vinieron de la parte del norte, los cuales pintaron en el territorio de su misión una cueva que él mismo fue a ver; la cual es casi tan grande como la otra de la misión de San Ignacio: esto es, como diez varas de largo, cinco o más de ancho y seis de alto con poca diferencia; mas no está en forma de bóveda, sino de cielo raso, formado de una sola peña tan gruesa y firme que mantiene sobre sí un alto cerro. Este cielo raso está pintado y lleno de figuras ya de animales y ya de hombres armados de arcos y flechas, representando las cazas de los indios. Estas pinturas se conservan bien claras y perceptibles no obstante el estar sobre la desnuda piedra sin otro aparejo, y que en tiempos húmedos y de nieblas no pueden dejar de humedecerse el aire de la misma cueva. Por lo demás, dice que es pintura tosca; que está muy lejos de los primores de este arte. No obstante, da a entender que sus autores tenían más aplicación, más habilidad y más conocimientos que los naturales de este país.

Como la fama, mientras más se dilata, más aumenta las cosas, la memoria que quedó de la estatura de estos gigantes, comunicada de padres a hijos en el decurso de muchos siglos (aunque no sabemos cuánto, ni es posible averiguarlo entre los indios), esta memoria, digo, ha crecido tanto que dicen los de aquella tierra que los gigantes eran tan grandes que, cuando pintaban el cielo raso de la cueva, estaban tendidos de espaldas en el suelo de ella y que aun así alcanzaban a pintar lo más alto. (Del Barco, 1973).

El haber citado extensamente estas noticias tan comentadas por estudiosos - pero nunca tan puntualmente-, es para incorporarlas al análisis y la reflexion que ameritan. El no hacerlo asi, desdibuja su sentido y connotaciones originales. Es indispensable darles buen uso como referencia y necesario evitar alteraciones en las secuencias historicas mencionadas.

Un análisis cuidadoso de dichas referencias, muestra como fue que eso que hoy denominamos genéricamente y por comodidad académica pintura 
rupestre - que va desde los petrograbados hasta los grandes murales- fue extrafdo de la tradición cultural - muy probablemente milenaria - de los pueblos de cazadores-recolectores que poblaban y dominaban los territorios que los jesuitas denominaron California, para insertarla al discurso judeocristiano en lo referente a la existencia histórica de gigantes, como se describe en algunas partes del Génesis. Los grandes murales que encontro el padre Rotea se convirtieron en la prueba fehaciente de la existencia de gigantes en la península como parte de un discurso desinteresado, pero ligado a la tradición del Génesis.

Lo anterior quiere decir que la pintura rupestre terminó por ser subsumida en el discurso de los jesuitas para mostrar que los textos bíblicos, de una u otra manera, daban cuenta de la historia de la humanidad, aun entre aquellos pueblos conquistados en el llamado Nuevo Mundo. Esa actitud discursiva era ajena a la exactitud histórica y, por ello, su valor referencial es totalmente limitado y poco útil para el conocimiento de aquellos pueblos; aunque no se puede decir lo mismo para quienes lo escribieron.

Aquella subsunción forzada terminó por desvincular a los pueblos de cazadores-recolectores que conquistaron los jesuitas con aquellas expresiones pictoricas y petroglíficas. A tal grado lleg $\delta$ dicha desvinculación, que hasta hace no menos de cinco años era casi imposible pensar que existio alguna relacion entre esos pueblos y las manifestaciones pictóricas y petroglificas que en la actualidad encontramos por amplias zonas de la península californiana; como finalmente parecen sugerir las recientes investigaciones arqueologicas.

Los arqueólogos María de la Luz Gutiérrez y Justin R. Hyland, responsables del megaproyecto de Pintura Rupestre en la Sierra de San Francisco de sa península californiana, consignan en uno de sus más recientes artículos de difusion algunos de sus resultados. De los cuales, los más importantes son los fechamientos de material arqueológico en contexto, localizados en la Cueva del Ratón. Estas fechas, refieren dichos arqueologos:

van de 334 a.C. hasta 1655 d.C., por lo que resultan sumamente intrigantes ya que sugieren un periodo de cuatro mil años de la tradición Gran Mural, una tradición que los estudiosos han notado por su llamativa homogeneidad estilística y de contenido.

\section{Y más adelante agregan:}

Lo que es sumamente interesante es que ninguna de las 59 dataciones realizadas hasta el momento por el proyecto arte rupestre de Baja California corresponda al periodo sugerido por las dos fechas más antiguas de 
los estudiosos del equipo de Barcelona, pues sólo hay una fecha: 8,500 a.C.; la siguiente es 1350 a.C., y el $85 \%$ del total de las fechas son posteriores al comienzo de nuestra era (Gutiérrez y Hyland:88-89).

Señalado lo anterior, queda como una incógnita a resolver las fechas más tardías que pueda encontrar la arqueología para la tradición del gran mural, pues no afectan -de momento- nuestra exposición. Pero pongamos atención en las fechas que se acercan a nuestra era, e incluso a la era del inicio de la conquista jesuítica de los pueblos de cazadores-recolectores que habitaban y dominaban la porción meridional de la península.

Sorprende que algunas fechas lleguen a años muy cercanos al inicio de la conquista jesuítica, 1694 d.C., debido a que ello nos indicaría que los pueblos de cazadores-recolectores conquistados por los jesuitas, estaban inmersos, como herederos, trasmisores y redimensionadores no sólo de las formas de vida material de sus antepasados, sino también de sus distintas manifestaciones espirituales y culturales como podrían ser, entre otras tantas, las expresiones pictóricas o de petrograbado. Podemos constatar que aquellos hombres y mujeres que estaban conquistando los jesuitas no sólo tenían presente, sino pasado y - lo más importante - memoria de ello. Elemento vital, este último, no sólo para mantener su vida, sino también para enriquecer y redimensionar sus conocimientos históricos y de lo histórico. Aspectos que apuntaban hacia una perspectiva de futuro, como lo habian tenido sus antepasados.

Hasta hace muy poco, la vinculación directa entre los pueblos existentes en el momento de la llamada conquista espiritual y la tradición de la llamada pintura rupestre era inaceptable. Advertirlo ahora adquiere relevancia y cambia de rumbo las explicaciones y concepciones que en la actualidad se tienen de los pueblos indios que conquistaron tanto los jesuitas como, después, los franciscanos y dominicos en el septentrión californiano.

El que Clavijero y Del Barco, al momento de escribir sobre este particular, hayan desvinculado a las poblaciones nativas que estaban conquistando de aquellas manifestaciones culturales, apunta a una línea de explicación que era coherente con su idiosincrasia pero no con lo que sucedía entre los pueblos de la llamada California.

El discurso se sustenta en la continuidad de negarles a los pueblos conquistados, cualquier rasgo de humanidad y, por ende, de expresiones culturales tan palpables como podrían ser la llamada pintura rupestre. La innegable existencia de las mismas les hizo escribir que éstas se debían a creaciones de otros pobladores muy superiores y antiguos a los que estaban conquistando. Que aquellos antiguos hombres habían sido los primeros 
pobladores de esas tierras. El apoyo indiscutible de ese aserto eran justamente los murales que describieron.

La superioridad de esos hombres, pensaban los jesuitas, no sólo se notaba en dichas pinturas, sino también en sus grandes medidas corporales que les permitieron pintar aquellas figuras que se asemejaban a ellos y que explicarían no sólo las dimensiones de las mismas, sino también las partes en que las habían realizado.

De todo lo anterior, Clavijero y Del Barco concluyeron la diferencia entre los hombres que realizaron esos murales y los pueblos que estaban conquistando. Por ello, aseveraban que los pueblos en proceso de conquista y conversión no sabían con certeza qué significaban aquellas expresiones culturales, cuándo se habían pintado y qué ceremonias se realizaban frente a ellas.

Si las fechas y hallazgos establecidos por la investigación arqueologica reciente son ciertos, no podemos seguir pensando que los distintos pueblos conquistados por los jesuitas a finales del siglo XVII y buena parte de la primera mitad del siglo XVIII, hubiesen sido del todo ajenos a aquellas manifestaciones pictóricas ni a las ceremonias que allí se realizaban. Luego entonces, ¿cómo ir más allá de las explicaciones planteadas por Clavijero y las de Del Barco?

Para entrar en materia, es necesario establecer los aspectos cronológicos que son indispensables para el análisis subsecuente.

De las extensas citas que hemos hecho del padre Miguel del Barco y de Francisco Xavier Clavijero, hay que decir que ellos fueron los primeros y únicos jesuitas que consignaron la existencia de estas manifestaciones pictóricas, así como de la narrativa "gigantológica" que las acompaña.

Si observamos minuciosamente los escritos de los jesuitas que conquistaron las Californias, nos daremos cuenta que en ninguno de ellos, antes de Clavijero y de Del Barco, refieren la existencia de los grandes murales ni la narrativa de los gigantes. Ni aun en la primera gran obra que se public 6 a mediados del siglo XVIII (1756) sobre las Californias - y que bien a bien debe atribuírsele al jesuita residente en Nueva España Miguel Venegas y al jesuita español Andrés Marcos Burriel: Noticias de la California y de su conquista espiritual-, hay referencia a las pinturas o a la narrativa de los gigantes que las acompañaban.

En dichas Noticias se afirma:

Todas las relaciones convienen, que entre los californios no se ha hallado hasta ahora idolatría: porque ni adoraban a criaturas algunas, ni tenían figuras o ídolos de falsas deidades a quienes tributasen algún linaje de culto. Tampoco había entre ellos templos, oratorios, altares 
u otro lugar alguno deputado para los actos de religión: pues ni aun actos de religión había o profesión exterior de ella, en fiestas, oraciones, votos, expiaciones, o algunas otras prácticas de reconocimiento a dios, públicas o privadas (Venegas y Burriel, 1943:88).

$\mathrm{Ni}$ en esta referencia ni en las subsecuentes páginaś del citado libro sugieren ningún indicio de la existencia de las pinturas y la narrativa de los gigantes; lo que mostraría que Del Barco y Clavijero no mintieron al decir que se tuvieron noticias de ellas muy poco antes de que se expulsara a los jesuitas de la península califomiana.

Este aserto cronológico no sólo tiene como objeto precisar un acontecimiento historiográfico, sino que debe llevamos a una pregunta hasta el momento no planteada: ¿por qué aquellas manifestaciones pictóricas fueron conocidas por los jesuitas muy poco antes de 1768 -año de su expulsión-. Y, consecuentemente, ¿por qué no había noticias de la narrativa de los gigantes que supuestamente, como señalan Clavijero y Del Barco, eran tradiciones orales muy antiguas entre los aborigenes? $\mathrm{O}$, dicho en otros términos, ¿por qué no existen antes de Clavijero y de Del Barco estas referencias entre Kino, Piccolo, Bravo, Ugarte, Helen, Luyando, Baegert, etcétera, quienes recorrieron los territorios circunvecinos a la sierra de San Francisco, para convertir a los aborígenes asentados en aquellas regiones que comenzaron a reconocerse y dominarse a partir de la fundación de la misión de Santa Rosalía de Muleje, en 1705, y que se continuó hacia el occidente y septentrión penínsulo-californiano con las de Guadalupe (1720), San Ignacio 1728 y Santa Gertrudis 1752?

Para continuar en esta línea, habria que preguntarnos si los jesuitas que fundaron y habitaron en las misiones de Santa Rosalia, Guadalupe, San Ignacio y Santa Gertrudis, antes de 1768 - cuando el padre Rotea dio con ellas-, hicieron bien su trabajo en el sentido de indagar y conocer a profundidad los territorios y a los hombres y mujeres que estaban conquistando, tal y como lo exigfa su ministerio y, consecuentemente, dar cuenta de ello.

Por la documentación que poseemos - básicamente correspondencia de jesuitas-, no podemos menos de reconocer que todos los misioneros que acudieron a los territorios llamados las Californias, pusieron lo mejor de sí para cumplir con sus dos majestades - la divina y la terrena, como ellos mismos decían-, al tiempo que daban cuenta de lo ocurrido. Luego entonces, ¿qué sucedio?

¿Sería posible presumir, hoy en día, que a los primeros jesuitas que llegaron a la península, les pareciera irrelevante y sin pruebaalgunaaquella tradición oral de la "gigantología" que narran Clavijero y Del Barco y, por lo tanto, no la consignaron en sus cartas y escritos? 
Dicha presunción se anula al constatar que tal narrativa de los gigantes, por lo menos, les hubiese sido muy conveniente, ya que desde los primeros jesuitas que llegaron al denominado Nuevo Mundo, anduvieron siempre buscando indicios, por mínimos que fueran, de que los habitantes de este continente tuvieron alguna relación con hechos correspondientes a la tradición judeocristiana de la creación y propagación del género humano por todos los continentes.

Una historia de gigantes en este continente nunca hubiera sido mal vista por los jesuitas; por el contrario, se habría propagado. Pues con ello la tradición judeocristiana occidental encontraba de inmediato - aunque entre tinieblas - un correlato con aquel pasaje del Génesis donde se habla de los gigantes; como lo hiciera un siglo antes fray Diego Durán, José de Acosta y fray Juan de Torquemada. (Véase el apartado que hemos denominado "Tradición de gigantologia").

De esta manera, queda descartada la posibilidad de que los jesuitas conquistadores de la penf́nsula hasta antes de 1768, hicieran caso omiso a una tradicion oral como la de los gigantes. Luego entonces, lo único que se antoja como posible - ante la falta de esa narrativa de los gigantes de parte de los jesuitas anteriores a Rotea-, es que esa narrativa se urdio cuando los jesuitas ya estaban en el exilio.

Como apoyo a la reflexión anterior, en primer lugar tendríamos que no existe nota o escrito prolífico sobre los hallazgos que hizo el padre Rotea durante el periodo de estancia de aquel jesuita en la misión de San Ignacio. Esto es desde 1762, fecha de la fundación de la misión de San Ignacio, hasta 1768, año de la expulsión de los jesuitas y consecuente abandono de la misma. Y, por otra parte, es inexplicable la ausencia de esta noticia durante esos años, dado que la importancia de la misma la consignarán más tarde los textos de Clavijero y Del Barco.

A más de lo anterior, tendríamos que el texto que Del Barco nos presenta como de la pluma de Rotea, apuntaría a que es un escrito meditado, elaborado para contar la historia de los gigantes y cuyo aval serfan las osamentas y las propias pinturas. Así pues, los objetos no eran relevantes, ya que lo que verdaderamente importaba era dar a conocer al mundo la existencia de gigantes en el llamado continente americano como una señal meramente casual, pero que refrendaba algunas partes del Génesis y que era importante confirmar a finales de un siglo que comenzaba a profundizar en la crítica interna de los textos bíblicos y, consecuentemente, a desechar las partes — diríamos - más mitológicas.

Podemos afirmar que a diferencia de fray Diego de Durán, José de Acosta o fray Juan de Torquemada, la "gigantologia" penínsulo-californiana se creo y recré en el exilio jesuítico y no en las propias tierras 
americanas, y que después llegó a éstas cuando las obras de esos jesuitas se divulgaron entre los actuales pobladores de la misma.

Para terminar con esta parte del análisis del discurso de la "gigantología" en las Californias, sólo nos resta llamar la atención sobre el hecho de que ni Clavijero ni Del Barco hayan reparado en los símiles existentes entre esa narrativa de los gigantes y la judeocristiana; y que ni siquiera las hayan calificado como invenciones ni inverosímiles, como sí lo hicieron con otras tantas que tendrían más visos de originalidad prehispánica.

Ya en las noticias de Venegas-Burriel se advertía:

Nada hay que tanto deba interesar la curiosidad, ni que pida examen más atento y profundo, que todo lo que toca a la antigua religión de los californios. El uso que puede hacerse de semejantes noticias a favor de nuestra Santa Religión Cristiana, se ve bien en la demostración Evangélica del celebérrimo Obispo de Avranches Pedro Daniel Huecio, que con vastísima erudición recorre todas las varias sectas antiguas y modernas de las Naciones del Orbe, aun de las Americanas, para sacar de entre sus tinieblas, apoyos a la luz de la verdad de nuestra Santa Fe..., tales noticias podrían confrontarse con las que ya se tienen de las Sectas y Religión, así de los mexicanos, peruanos y otros pobladores del Nuevo Mundo, como de las Naciones más Orientales del Asia, Japón, Chinos, Tártaros, Coreos, Mantcheos, Kamchatkos, y Iracuktos, ya conocidas y registradas. Sin embargo, este es uno de los puntos en que es preciso quedarse con muchas dudas y con deseos de mayor instrucción.

Luego de narrar algunas mitologías de los edúes o pericúes, laymones, monquies, vehities, guaycuros y cochimíes, señala:

Éstos y algunos otros eran los Dogmas de los Cochimíes que yo quisiera poder referir a la larga con entera seguridad, de que los indios recién convertidos no han querido lisonjear a los Misioneros, dándoles a entender, que ellos, antes de su conversión, tenían Dogmas muy parecidos a los que se les acababan de anunciar. Y también quisiera poder referirlos con los nombres mismos de sus lenguas, con exacta crítica de su verdadera significación e inteligencia, y con prolija averiguación de si acaso alguna tempestad u otro accidente, llevó a la una o a la otra costa de las Californias a alguno o algunos Europeos o Filipinos, de quienes ya no haya memoria entre los indios, el cual o los cuales, hallándose en medio de bárbaros, procuró inspirarles los misterios de la Religión Cristiana el tiempo de viviese; y después se hayan desfigurado entre los indios las noticias, pasando de unos a otros, hasta que las encontraron así desfiguradas los Misioneros (Venegas y Burriel, 1943:91-92). 
Del Barco y Clavijero no repararon en esas reflexiones y advertencias que debieron ser comunes entre los misioneros y religiosos de aquel tiempo. La explicación puede resultar clara si consideramos que no tenían ningún interés en reparar en ellas porque lo que querían y pretendían era justamente mostrar lo extendido de la tradición gigantológica, como una narrativa verdadera, independientemente de cualquier grupo étnico y con lo cual pretendían avalar aquella tradicion, que justamente por esos años estaba siendo discutida en Europa. Y, en todo caso, si la narrativa de la "gigantología" en las Californias fue referida por los catecúmenos de la misión de San Ignacio, no podemos más que pensar en que éstos se las contaron a los misioneros con el ánimo de lisonjearlos, como bien advirtieron Venegas-Burriel.

Pero si lo anterior tiene rasgos de verosimilitud, lo que no puede estar en cuestión es que el padre Rotea, en algún momento de su estancia en la misión de San Ignacio vio aquellos grandes murales. Pues su descripción concuerda con los que hoy existen.

Teniendo ya separada la cuestion de que la narrativa de los gigantes tiene poco que ver con las propias manifestaciones pictóricas que vio Rotea, se antojan hacer una serie de preguntas como: ¿por qué otros jesuitas no vieron aquellas pinturas y otras manifestaciones culturales que estaban seguramente asociadas a ellas? Si las observaron, ¿por qué no le dieron ninguna importancia, aunque sólo fuese en sus cartas?

La segunda pregunta encuentra algún tipo de respuesta si se entiende a su máximo extremo el discurso colonialista de negarles todo, absolutamente todo tipo de actividad humana, a quienes se estaba conquistando.

Por lo que hace a la primera pregunta, podemos suponer que simple y sencillamente los pueblos circunvecinos y aun los que ocupaban por mayor tiempo la sierra de San Francisco, nunca llevaron a los jesuitas a los resguardos y abrigos donde se hallan las grandes pinturas murales; y que finalmente el padre Rotea los encontró de manera accidental.

Pero detengámonos brevemente en esto, pues nos ayudará a limpiar el camino y poder entender mejor lo que sucedió. No es descartable el hecho de que algunos catecúmenos del padre Rotea hayan encontrado, casualmente llendo de cacería, algunas osamentas en la sierra y que las mismas hayan sido llevadas hasta el misionero. Él, al tenerlas frente a sí, inició una averiguación para indagar a quiénes pertenecían.

Ya estando en la sierra, en el lugar donde se encontraron las osamentas, recorrio exhaustivamente el lugar para poder tener claro la pertenencia de las mismas. Es muy probable que durante ese recorrido haya encontrado el abrigo rocoso donde estaban pintadas aquellas figuras que después describio. 
Es muy probable que en el momento en que vio aquellos murales, no le parecieran tan importantes como para dar noticia a sus superiores. Esta percepción sólo tomó relevancia cuando ya estaba en el exilio y-donde sabemos-muchos de los jesuitas se dieron a la tarea de revisar tanto sus actuaciones como de reflexionar sobre las mismas. Este trabajo no s6lo fue la forma que encontraron para permanecer vivos, sino también para ampliar y dar a conocer su labor evangélica, tan cuestionada en esos mismos años.

Pero aparte de todo esto, sigue estando pendiente la pregunta que en algún momento se hizo Rotea: ¿a quiénes pertenecf́an aquellas osamentas? Ya sabemos que él se lo atribuyó a gigantes, pero ello debió ser cuando estaba en Europa y ya muchos años después, cuando nadie podía comprobar nada sino simplemente creer en las letras del misionero.

El que fuesen gigantes, queda pues descartado. Lo más plausible es que fuesen cadáveres de aborigenes que no aceptaron la vida misional y, que por lo tanto, mantenfan vivas muchas de sus tradiciones, asf como de sus usos y costumbres, que eran totalmente condenadas por los misioneros. Por lo cual dar una noticia de ese tipo era inaceptable. Por ello a Rotea y a sus hermanos de orden les pareció mucho mejor y más acorde con su idiosincrasia el convertir a aquellas osamentas, junto con los grandes murales que describieron en los testimonios fehacientes de la existencia de gigantes en la península.

Del anterior razonamiento, podemos entonces deducir que un número indeterminado de indígenas permaneció al margen de la vida misional $y$, por lo tanto, de la conquista espiritual. Para lograr lo anterior, la sierra de San Francisco siguio siendo - para aquellos pueblos - un reducto de vida material y espiritual; y ya no como antes, un espacio más de la producción y reproducción de su vida.

Lo anterior nos estaría hablando, contrario de lo escrito por los jesuitas y de muchos historiadores actuales, que no todos los integrantes de los pueblos cazadores-recolectores fueron atraidos a la vida misional y que quizá muchos permanecieron al margen de ella como una actitud de resistencia para no ser subsumidos en los nuevos modos de vida que se les imponían.

Si eso fuese cierto, estarfamos ante la presencia de la division de los pueblos de cazadores-recolectores como producto mismo de la llamada conquista espiritual. Esta division se dio porque hubo quienes aceptaron el mundo misional y los que se resistieron a pertenecer a él, y así preservar sus usos y costumbres, aunque bajo las nuevas circunstancias que imponfa la conquista. Esto es, de una manera restringida, aunque solo fuese territorialmente, ya que de muchas tierras que antes utilizaban y recorrfan, se 
volvieron territorios vedados dada la ocupación de los misioneros y sus huestes militares.

Ahora bien, examinemos esto último que tiene rasgos de verosimilitud. Una primera hipotesis apuntarfa hacia la probabilidad de que los nativos de la sierra de San Francisco y aun los de las regiones circunvecinas a ella, ocultaron durante más de medio siglo a los jesuitas, la pintura llamada rupestre y en el momento en que ya no pudieron ocultarlos más, recurrieron a la falsificación y adulteración de sus tradiciones. Pero cabría también la posibilidad de que los catecúmenos que fueron interrogados para dar noticias de los grandes murales, ya no supieran nada de ellas, porque sencillamente ya no pertenecfan a la tradición cultural que los crearon; aun cuando éstas fueran pertenencias de sus antecesores más inmediatos. Por tanto, cuando se les preguntó sobre la pintura mural, lo único que pudieron responder fue lo que les habían enseñado sus mentores jesuitas y que les sonaba plausible dentro de la tradición cultural misional.

Apoyados en la reciente datologia arqueologica y en los razonamientos que hasta aquí hemos realizado, se puede suponer que durante los primeros años de conquista y conversión, los pueblos de cazadores-recolectores aledaños a la región de la sierra de San Francisco y los moradores de la misma ocultaron a los misioneros, e incluso a sus párvulos, aquellas manifestaciones culturales, para que no fuesen descubiertas y consecuentemente destruidas o dañadas. Inclusive que aquellos resguardos, donde se encontraban los grandes murales, se convirtieron en lugares de reunion muy restringida para continuar celebrando rituales acompañados de relatos que seguramente haćan referencia a esos portentos pictóricos.

Esa actitud, sin lugar a dudas, nos estaría hablando de una consistente y premeditada resistencia creativa por parte de los pueblos cazadoresrecolectores ante los conquistadores, para no mostrarles a los misioneros todo lo concerniente a su mundo material y espiritual. Actitud que debieron tener, sobre todo, los primeros individuos a quienes les toc 6 vivir y padecer los inicios de la llamada conquista espiritual.

Lo anterior también quiere decir que los primeros catecúmenos, seguidores o adeptos de los misioneros, no revelaron en su totalidad sus tradiciones y manifestaciones materiales y espirituales, y resistieron esa tentación u obligación cristiana.

Con esas acciones, tales elementos culturales se fueron convirtiendo en patrimonio casi exclusivo de los que permanecieron en actitud de resistencia al contacto misional. Con lo cual ese patrimonio cultural se fue quedando en la memoria de cada vez menos individuos, dado el embate a muerte de que eran objeto aquellos que no aceptaban el nuevo orden. Esto propició que los aborígenes que aceptaban la vida misional, terminaran por 
ignorar el mundo espiritual y material practicados aún por sus congéneres que permanecían en resistencia.

Dichas actitudes no pueden considerarse - bajo ninguna circunstancia-, como individuales o seleccionadas al azar. Al contrario, esto es: tomadas bajo consenso de los pueblos cazadores-recolectores involucrados (los que se unieron y no a la vida misional), ya que de otra manera no se explica lo sucedido. Lo anterior nos habla de la solidez y maduración cultural de los pueblos cazadores-recolectores que poblaban y dominaban el territorio, calificado por los conquistadores, californiano. Cultura donde lo fundamental pudo ser la aceptación de que unos salieran de su ámbito cultural e ingresaran a otro, mientras que otros permanecían en la región que les había dado pasado, presente y la posibilidad de futuro, sin que ninguna de estas opciones representara una traición para estos pobladores.

Lo anterior explicaría, en última instancia, el porqué los catecúmenos que vivieron y se reprodujeron dentro de la vida misional, después de varias generaciones ya no tuvieron recuerdos o memoria de lo que implicaban aquellas pinturas. Por lo tanto, la ruptura cultural entre aquellos pueblos de cazadores-recolectores no se dio antes de la conquista espiritual, cientos de años como quisieron hacernos creer los misioneros jesuitas, sino cuando éstos iniciaron su conquista y dominación.

La memoria histórica y de lo histórico era tan buena en aquellos hombres como entre otros pueblos que habitaban cualquier lugar de la tierra, porque si algo puede ser notado en la historia "prehispanica" de los habitantes de la llamada penf́nsula de California es su buena memoria, ya que sin ella su propia vida hubiese sido imposible. Para comer, caminar, reproducirse, etcétera, se requiere de memoria y conocimiento histórico y de lo histórico. Y si ella se fue consumiendo, se debe a que sus propios portadores fueron cada vez más cercados y aniquilados por la intransigencia dogmática de quien conquista bajo la idea de que lo suyo es lo único que debe de prevalecer, porque lo ajeno no es verdadero ni trascendente.

Hoy pensamos que esas manifestaciones pictograficas, petroglíficas y pictóricas tenían alguna relación con el interactuar del mundo material y espiritual que construyeron aquellos pueblos milenarios de cazadoresrecolectores y gracias al cual, pudieron vencer ese medio que en la actualidad parece tan hostil, pero que para ellos no lo fue tanto, ya que les permitio la construcción de sus propias historias. Historias sepultadas por la intransigencia dogmática de un discurso unificador y de escaso respeto para los otros, los ajenos, los diferentes; en fin, para quienes pudieron construir sus propias historias.

La revelación de esta última historia - la de la resistencia y sus consecuencias-, está todavfa por construirse y esclarecerse, no sollo porque 
ha sido acallada por la historia de una conversión rápida, sin violencia y, por último, sin resistencia. El ver de otra manera: deconstruida, las historias que nos dejaron los jesuitas, sin duda comenzará a sugerir otras tantas historias que siguen sin ser siquiera imaginadas.

Para finalizar, debemos hacer una precisión en cuanto a las fuentes historiograficas referidas:

Los lectores de finales del siglo XVIII pudieron tener referencia de los grandes murales localizados en la sierra de San Francisco de la península californiana a través de la lectura de la Historia de la antigua o Baja California, de Francisco Javier Clavijero, ya que ésta se publicó en Venecia dos años después de su muerte; es decir en 1789. En México se conoció gracias a la edición y traducción del presbítero Nicolás García de San Vicente en el año de 1852 y, en el siglo XX, gracias a la edición del Museo Nacional de Arqueología, Historia y Etnografía (1933). Su lectura se ha popularizado debido a la edición que en 1970 hizo la editorial Porrúa, precedida por un estudio de Miguel León Portilla.

La obra de Del Barco, que con toda seguridad fue comenzada años antes de que Clavijero emprendiera su obra, permaneció inédita hasta 1973, cuando Miguel León-Portilla hizo una edición de ella.

Como él mismo lo refiere, Clavijero se valió de la obra de Del Barco para tratar este tema de los grandes murales pictóricos de la sierra de San Francisco. Las diferencias de estructura pueden notarse a simple vista. En páginas anteriores hemos visto algo de la estructura que persegufa de Del Barco, ahora faltarfa sólo señalar que, para Clavijero, la inserción de este apartado tenía por objeto denigrar y menospreciar a los aborígenes, que sus hermanos de orden habian intentado catequizar, y cuyo último resultado todavía no divulgado por aquellos años era el del casi exterminio de aquellos mismos aborigenes.

\section{TRADICIÓN DE GIGANTOLOGÍA}

Fray Diego Durán, en su Historia de las Indias de Nueva España e islas de tierra firme es muy explícito en la creación de este tipo de impostaciones bíblicas, a partir de lo que le decían sus informantes. Según él, interrogó a un anciano de más de cien años para que le contara la visión que tenían en el México prehispánico acerca de los orígenes, y éste le contó:

En el principio, antes que la luz ni el sol fuese creado, estaba esta tierra en obscuridad y tiniebla y vacía de toda cosa creada. Toda llana, sin cerro ni quebrada, cercada de todas partes de agua, sin árbol ni cosa criada. Y luego que nació la luz y el sol en el oriente, aparecieron en 
ella unos hombres gigantes, de deforme estatura, y poseyeron esta tierra. Los cuales, deseosos de ver el nacimiento del sol y su ocaso, propusieron de lo ir a buscar. Y dividiéndose en dos partes, los unos caminaron hacia poniente, los otros hacia oriente.

21. Estos caminaron hasta que la mar les atajó el camino, de donde determinaron volverse al lugar de donde habían salido, y vueltos a este lugar, que tenía por nombre iztac zulin inemian, no hallaron remedio para poder llegar al sol, enamorados de su luz y hermosura, determinaron de edificar una torre tan alta que llegase su cumbre al cielo, y llegando materiales para el efecto, hallaron un barro y betún muy pegadizo, con el cual a mucha prisa empezaron a edificar la torre. Y habiéndola subido lo más que pudieron, que dicen que parecía llegar al cielo, enojado el Señor de las alturas dijo a los moradores del cielo:

22. "¿Habéis notado cómo los de la tierra han edificado una alta y soberbia torre para subirse acá, enamorados de la luz del sol y de su hermosura? Venid y confundámoslos, porque no es justo que los de la tierra viviendo en la carne, se mezclen con nosotros". Luego en aquel punto salieron los moradores del cielo por las cuatro partes del mundo, así como rayos, y les derribaron el edificio que habían edificado. De lo cual asombrados los gigantes y llenos de temor, se dividieron y derramaron por todas las partes de la tierra.

23. Bien creo que será necesario advertir al lector que note el capítulo 1 y 2 del Génesis en lo que hemos venido tratando, pues tan manifiestamente vemos relatar a un indio la creación del mundo y lo que en el capítulo 2 del mismo libro trata, de los gigantes y de la torre de Babilonia y del cómo la edificaban los hombres codiciosos de llegar al cielo, movidos sólo por celebrar su nombre, por lo cual fueron confundidos de Dios. Y así me persuado y deseo persuadir que los que dan esta relación la oyeron de sus ascendientes y antepasados. Y estos naturales, como son de la línea de aquel pueblo escogido de Dios (según mi opinión), por quien Dios obró grandes maravillas, ha venido la noticia y pinturas de mano en mano, de las cosas de la Biblia y misterios de ella para atribuirlo a esta tierra y qué aconteció en ella, ignorando el principio.

24. No niego, ni puedo negar, que haya habido gigantes en esta tierra, pues como testigo de vista, lo puedo afirmar, pues los conocí en algunos lugares de las, de disforme estatura. Y porque creo que de esto habrá quien de esto se acuerde en México, en la procesión del Corpus vi sacar un indio de estos gigantes, vestido de tafetán amarillo, con una parte sana al hombro y una celda en la cabeza, que sobre todo sobrepujaba una vara de medir. 
22. La otra gente que dicen que hallaron los de Tlaxcala y Cholula y Huejotzinco, dicen que eran gigantes...

23. Hállanse hacia aquellos lugares huesos de gigantes grandísimos, los cuales yo muchas veces he visto sacar en lugares ásperos,-donde, huyendo de los cholultecas, se despeñaban y echaban a morir..., que no los dejaron, hasta que dieron fin de ellos. (Duran, 1967:17-18).

Fray Juan de Torquemada, en su Monarquía indiana, dedica un capítulo (XIII, libro I) a los gigantes como los, "primeros moradores de estas indianas tierras antes de los toltecas". Y escribio:

Supuesto que a tantos mil años que pasó el Diluvio e inundación general con que Dios castigó a los moradores del mundo, y que después acá de este universal anegamiento se volvió a poblary henchir de gente que procedieron de Noé y sus tres hijos (que fueron los que por mandamiento de Dios, entraron en el Arca y en ella se salvaron) digo: que habiendo sido de estos dichos (o descendientes de ellos) lo que habitaron y poblaron las tierras (tomando cada cual nombre y apellido, como más a su propósito y plácito hizo) decimos consecutivamente que los que hasta ahora se sabe haber morado estas extendidas y ampliadísimas tierras y regiones de la Nueva España, fueron unas gentes muy crecidas de cuerpo que llamaron después otros quinametin (que quiere decir gigantes), porque sin duda los hubo en estas provincias cuyos cuerpos han aparecido en muchas partes de la tierra cavando por diversos lugares de ella; y hemos visto sus huesos tan grandes y desemejados que pone espanto considerar su grandeza. De donde hubiesen venido estos gigantes áca, no se sabe; pero sabemos que antes del Diluvio, dice la Sagrada Escritura (Génesis 6), que había gigantes sobre la tierra que nacieron de las hijas de los hombres que se copularon con los hijos de Dios. Que si tomamos el parecer de muchos hombres doctos fueron éstos los mayores, así en dignidad como en cuerpo, de los de la república, escogiendo también mujeres corpulentas y muy crecidas para sus ayuntamientos (según lo nota Oleastro sobre el capítulo sexto del Génesis). Y dejando aparte el averiguar de qué gentes habían nacido, sólo digo, haberlos habido en el mundo, en aquellos primeros tiempos de él, diciendo la Sagrada Escritura: que había gigantes sobre la tierra, en aquellos días; y aprovechándose el excelentísimo doctor San Agustín de este lugar, dice: que no hay duda, sino que antes del Diluvio hubo muchos gigantes y que estos estuvieron avecindados con los otros hombres del mundo. Luego más abajo de estas palabras, dice: haberlos criado Dios para mostrar en su creación y grandeza no sólo debe ser alabado en la hermosura y bizarría de las cosas, sino también en su hechura y grandeza. Y cita luego a Baruch, que dice: allí hubo gigantes, varones 
muy nombrados, que desde los principios fueron fuertes y grandes guerreros. Theodoreto, contradiciendo a los que niegan no haber sido los gigantes mayores que los otros hombres del mundo, dice en una cuestión que hizo contra ellos: pero yo, cuando oigo la divina escritura, que dice: que Enach, gigante, nació de gigantes; y que el lecho y cama del rey $\mathrm{Og}$, que era de hierro y de nueve codos en largo y de ancho cuatro; y cuando oigo a los exploradores de Jesús que cuentan que los hebreos que iban entrando a la tierra de promisión eran langostas, en comparación de los gigantes que moraban la tierra; y a Dios, que dice: entregué a Amorreo, cuya altura y grandeza era del tamaño de un cedro y sus fuerzas de un roble, pienso haber algunos muy grandes hombres, dispensando en su naturaleza y grandeza, el sapientísimo Dios, para que los que le conocen omnipotente en la creación, echen también de ver cómo lo muestra el hacer unos hombres mayores que otros. Beroso Anniano, en el principio de su historia dice: que halló escrito que en aquellos primeros siglos del mundo, antes del general anegamiento de los hombres, había una ciudad junto al monte Líbano llamada Henos, que era de gigantes que se enseñoreaban de toda la tierra, desde oriente a poniente; $y$ luego dice muchas ciudades de estas gentes muy propias de gente poderosa, fuerte y atrevida; de manera que por lo dicho queda probado haberlos habido en el mundo, no en pequeño, sino en un cuantioso número... (De Torquemada, 1975-85:51-52).

Siendo pues esto así verdad y siéndolo también que los hubo en esta tierra de la Nueva España, está ahora la duda en si los huesos que ahora parecen de estos desemejados gigantes fueron de antes del Diluvio o después de él, para cuya inteligencia digo que he tenido en mi poder una muela, que para estar entera le falta poco y es dos veces tan grande como el puño y tan pesada, que tiene de peso más de dos libras; y enseñándola a un hombre llamado Pedro Morlet (francés de nación, natural de la ciudad de París, hombre peritísimo en el arte de la escultura) y diciéndole, ¿qué le parecía de aquel tan monstruoso hueso?, me dijo: que en el convento de San Agustín, de esta ciudad de México, acababa de ver aquel día un hueso que parecía ser de muslo y que según su tamaño era todo el cuerpo de más de once o doce codos (cosa monstruosísima) y añadió diciendo que era de gigante, de los tiempos del Diluvio, y preguntándole: ¿que cómo lo sabía?, respondió que en no sé qué parte de España (que no me acuerdo bien la que me nombró) cavando en una sierra, donde buscaba piedra para su arte y escultura, fue descubriendo muchas osamentas, como ya convertida en piedra, que parecían huesos de gigantes y que comunicándolo con otros dijeron: que fueron de aquellos que habían ahogado las aguas del Diluvio; porque así lo tenían de opinión muchos, que en otras partes, por allí cerca, habían dado con otros huesos de aquel mismo tamaño y que en aquellos tiempos se habían repartido por todas las 
tierras estos hombres grandes y tan crecidos. Y dado caso que esto no sea así, es cierto que fue verdad ésta, después del Diluvio y que los hubo en estos nuevos mundos; y se dice que hubo gran noticia en el Perú, de unos gigantes que vinieron a aquellas partes, cuyos huesos se hallan hoy en día de disforme grandeza, cerca de Manta y del Puerto Viejo; y en proporción, habían de ser aquellos hombres más que tres tanto mayores que los indios de ahora. Dicen que aquellos gigantes vinieron por mar $y$ que hicieron guerra a los de la tierra y que edificaron edificios soberbios, y muestran hoy un pozo hecho de piedra de gran valor. Dicen más, que aquellos hombres, haciendo pecados enormes y especialmente usándolo contra natura, fueron abrasados y consumidos con fuego que vino del cielo. Del tiempo que se pobló la provincia de Tlaxcallan (en esta Nueva España) se dice que habitaban aquellas tierras gigantes y que como llegaron los forasteros se la quisieron defender; pero los recién venidos, como viesen la desigualdad de las fuerzas de los moradores y cuánto se les aventajaban en valor, los aseguraron y fingiendo paz con ellos los convidaron a una gran comida y teniendo gente puesta en celada, cuando más metidos estaban en su borrachera hurtáronles las armas con mucha disimulación (que eran unas grandes porras y rodelas, espadas de palo y otros géneros). Hecho esto dieron de improviso en ellos; queriéndose poner en defensa y echando menos sus armas, acudieron a los árboles cercanos y echando mano a sus ramas, así las desgajaban como otros deshojaron solas las hojas; pero como al fin los advenedizos venían armados y en orden, desbarataron a los gigantes e hirieron en ellos sin dejar hombre a vida. El padre Acosta dice, que estos que hicieron esta matanza fueron los tlaxcaltecas que poblaron aquella ciudad; pero la verdad es que entraron en la posesión de su sitio como lo decimos en el libro de las poblaciones; y los que pienso que fuesen fueron los xicalancas y ulmecas, que fueron primero que los tlaxcaltecas (como allí decimos); a los cuales no se trata que tuviesen guerra con gigantes. Y nadie se maraville ni tenga por fábula lo que decimos de estos gigantes; porque hoy día se hallan huesos de hombres de increíble grandeza y la muela, que en mi poder tuve, se sacó de una quijada que ya como tierra se iba desmoronando y haciendo ceniza; cuya cabeza, afirman muchos que la vieron (de los cuales son Fray Hierónimo de Zárate que era predicador y ministro de los indios del principal convento de Tlaxcala y Diego Muñoz Carmargo, gobernador de los mismos indios, que en esta dicha provincia... Estos gigantes se acabaron de todo punto sin quedar ninguna memoria de ellos. Dicen algunos que se murieron. Dicen algunos que se murieron de hambre, porque no comían lo que el cuerpo les demandaba y que andaban entre las gentes como bestias en el campo, no atendiendo a más que a comer y vivir la vida, hasta que les llegó la muerte. (De Torquemada, 1975-85:51-52). 


\section{BIBLIOGRAFIA}

Arqueología mexicana, octubre-noviembre 1994, vol. II, núm. 10.

CLAVIJERO, Francisco Javier. 1970. Historia de la antigua o Baja California. Estudio preliminar Miguel León Portilla, México, ed. Porrúa (Sepan Cuentos, 143).

DE TORQUEMADA, Fray Juan. Monarquía indiana. 3a. ed., 7 vols., preparada por el "Seminario para el Estudio de Fuentes de la Tradición Indígena" bajo la coordinación de Miguel León-Portilla, UNAM, México.

DURÁN, Fray Diego. 1967. Historia de las Indias de Nueva España e Islas de Tierra Firme, edit. Porrúa. vol.II.

DEL BARCO, Miguel. 1988. Historia natural y crónica de la antigua California, [adiciones y correcciones a la noticia de Miguel Venegas], edición, estudio preliminar, notas y apéndices: Miguel León-Portilla, México, Universidad Nacional Autónoma de México- Instituto de Investigaciones Históricas (Serie historiadores y cronistas de indias/3).

VENEGAS, Miguel y Andrés Marcos Burriel. 1943. Noticias de la California y de su conquista temporal y espiritual hasta el tiempo presente. Sacada de la historia manuscrita, formada en México año de 1739 por el padre Miguel Venegas de la compañía de Jesús; $y$ de otras noticias y relaciones antiguas y modernas, México, Editorial Layac, 3 vols. 